\title{
Experimental and numerical results of a high frequency rotating active magnetic refrigerator
}

Lozano, Jaime; Engelbrecht, Kurt; Bahl, Christian; Nielsen, Kaspar Kirstein; Barbosa Jr., J.R.; Prata, A.T.; Pryds, Nini

Published in:

Proceedings of the fifth IIF-IIR International Conference on Magnetic Refrigeration at Room Temperature

Publication date:

2012

Document Version

Publisher's PDF, also known as Version of record

Link back to DTU Orbit

Citation (APA):

Lozano, J., Engelbrecht, K., Bahl, C., Nielsen, K. K., Barbosa Jr., J. R., Prata, A. T., \& Pryds, N. (2012).

Experimental and numerical results of a high frequency rotating active magnetic refrigerator. In Proceedings of the fifth IIF-IIR International Conference on Magnetic Refrigeration at Room Temperature: Thermag V

\section{General rights}

Copyright and moral rights for the publications made accessible in the public portal are retained by the authors and/or other copyright owners and it is a condition of accessing publications that users recognise and abide by the legal requirements associated with these rights.

- Users may download and print one copy of any publication from the public portal for the purpose of private study or research.

- You may not further distribute the material or use it for any profit-making activity or commercial gain

- You may freely distribute the URL identifying the publication in the public portal 


\title{
EXPERIMENTAL AND NUMERICAL RESULTS OF A HIGH FREQUENCY ROTATING ACTIVE MAGNETIC REFRIGERATOR
}

\author{
J.A. LOZANO ${ }^{(a, b)^{* *}}$, K. ENGELBRECHT ${ }^{(a)}$, C.R.H. BAHL ${ }^{(a) *}$, K.K. NIELSEN ${ }^{(a)}$, J.R. \\ BARBOSA Jr. ${ }^{(b)}$, A.T. PRATA ${ }^{(b)}$, N. PRYDS ${ }^{(a)}$ \\ ${ }^{\text {(a) }}$ Department of Energy Conversion and Storage \\ Technical University of Denmark (DTU) \\ Frederiksborgvej 399, DK-4000 Roskilde, Denmark \\ *e-mail: chrb@dtu.dk \\ (b) POLO - Research Laboratories for Emerging Technologies in Cooling and Thermophysics \\ Department of Mechanical Engineering \\ Federal University of Santa Catarina (UFSC) \\ Florianopolis, SC, 88040-900, Brazil \\ **e-mail: jaime@polo.ufsc.br
}

\begin{abstract}
Experimental results for a recently developed prototype magnetic refrigeration device at The Technical University of Denmark (DTU) were obtained and compared with numerical simulation results. A continuously rotating active magnetic regenerator (AMR) using $2.8 \mathrm{~kg}$ packed sphere regenerators of commercial grade gadolinium $(\mathrm{Gd})$ was employed. With operating frequencies up to $10 \mathrm{~Hz}$ and volumetric flow rates up to $600 \mathrm{~L} / \mathrm{h}$, the prototype has shown high performance and the results are consistent with predictions from numerical modelling. Magnetocaloric properties of the $\mathrm{Gd}$ spheres were obtained experimentally and implemented in a one-dimensional numerical AMR model that includes also the parasitic losses from the prototype. The temperature span for a thermal load of $200 \mathrm{~W}$ as a function of frequency was measured and modelled. Moreover, the temperature span dependence on the cooling capacity as a function of cycle frequency was determined. It was found that thermal losses increase as the frequency increases. Therefore, a detailed study of these parasitic losses was carried out experimentally and numerically.
\end{abstract}

\section{INTRODUCTION}

It has been suggested that high frequency AMR devices will allow for higher cooling power per mass of magnetocaloric material and temperature spans ( $\mathrm{Yu}$ et al., 2010). Most of the developed magnetic refrigerators work with permanent magnets and gadolinium $(\mathrm{Gd})$ as magnetocaloric regenerative bed. Okamura et al. (2007) obtained a maximum cooling capacity of $140 \mathrm{~W} / \mathrm{kg}$ at $0.5 \mathrm{~Hz}$ and a cooling capacity of $40 \mathrm{~W} / \mathrm{kg}$ with a temperature span of $5 \mathrm{~K}$ with a magnetic field of $1.1 \mathrm{~T}$. Tura and Rowe (2011) achieved a cooling capacity of $455 \mathrm{~W} / \mathrm{kg}$ at $10 \mathrm{~K}$ span and no thermal load temperature span of $29 \mathrm{~K}$ with a magnetic field of $1.4 \mathrm{~T}$ and a maximum operating frequency of $4 \mathrm{~Hz}$. Russek et al. (2010) demonstrated a maximum zero-span cooling capacity of $948 \mathrm{~W} / \mathrm{kg}$ and a cooling capacity of $449 \mathrm{~W} / \mathrm{kg}$ with a temperature span of $10 \mathrm{~K}$ at $4.7 \mathrm{~Hz}$ employing a magnetic field of $1.4 \mathrm{~T}$.

Experimental results for the device presented in this work for cycle frequencies up to $10 \mathrm{~Hz}$ show that the performance begins to degrade at higher frequencies with the optimum operating frequency near 2 $\mathrm{Hz}$. In order to understand the results, the system is studied using a 1D AMR model developed by Engelbrecht et al. (2007). During the modelling phase of this work, focus was put on using accurate magnetocaloric properties as an input for the model, understanding frequency-dependent parasitic losses and understanding thermal parasitic losses. Magnetocaloric properties were measured on the 
commercial grade gadolinium taking into account the demagnetizing field in the measured sample. In the current experiments, frequency-dependent losses were studied while keeping all other operating conditions constant and the frequency was varied. The temperature span of the device decreases with increasing cooling power, allowing cooling curve experiments to be used to study thermal losses. The loss analysis is used to suggest design improvements.

\section{EXPERIMENTAL}

Experiments on a rotating active magnetic refrigerator device at DTU (Fig. 1) working with a 4-pole static permanent magnet and 24 rotating regenerator beds were carried out at frequencies up to $10 \mathrm{~Hz}$. The permanent magnet has a peak flux magnetic density of $1.24 \mathrm{~T}$ in the high field regions and it is close to $0 \mathrm{~T}$ in the low field regions (Bjørk et al., 2010). The regenerator beds consist of commercial Gd spheres sieved to diameters between 0.25 to $0.8 \mathrm{~mm}$ and packed with a 0.36 porosity. The dimensions of the beds are $100 \mathrm{~mm}$ in the flow direction and a cross section of $12.5 \mathrm{~mm}$ width by 18.6 $\mathrm{mm}$ height. These beds are rotated inside the magnet by an electrical motor with a variable rotation speed that is controlled by a frequency inverter. The volumetric fluid flow rate is manually controlled by a bypass valve at the outlet of a constant flow rate pump. At the cold end, the thermal load is simulated by an electric resistance heater, and the hot end temperature, $T_{\mathrm{H}}$, is controlled by a heat exchanger in contact with a water chiller. More details on the design and operation of the device are presented in Bahl et al. $(2011,2012)$ and Engelbrecht et al. (2012).

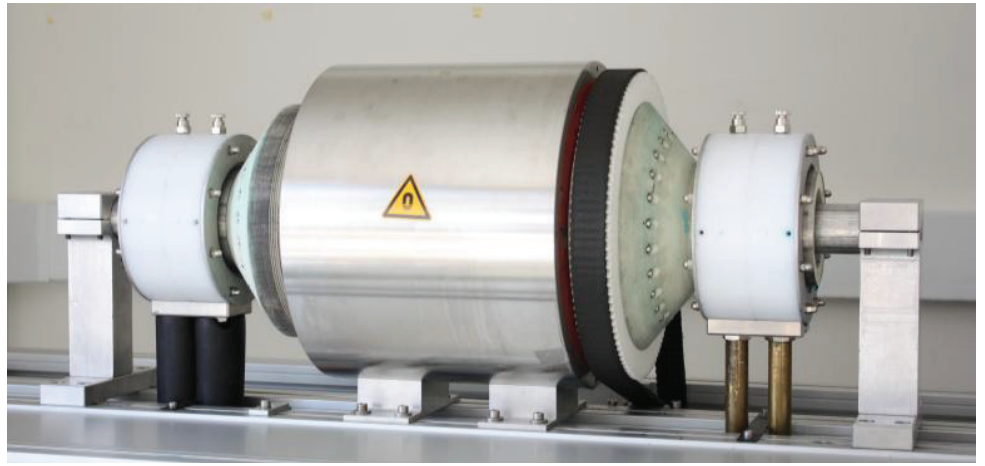

Figure 1. Rotating active magnetic refrigerator at DTU.

In this work, two different sets of experiments were carried out. First, the temperature span as a function of the frequency with a constant thermal load of $200 \mathrm{~W}$ was investigated. Then, the temperature span as a function of the cooling capacity at different frequencies was examined. The experimental results were compared with numerical results from a one-dimensional numerical model described in Engelbrecht et al. (2007). The model was modified to simulate the conditions of this experimental device. A packed sphere bed correlation (Kaviany, 1995) was employed for heat transfer in the regenerator beds. For modelling purposes, the ambient temperature was assumed constant at 295 $\mathrm{K}$, which is a good approximation of the room temperature during the experiments.

The Gd spheres were characterized by a LakeShore 7407 Vibrating Sample Magnetometer (VSM) and a custom-built Differential Scanning Calorimeter (DSC) described in Jeppesen et al. (2008). The isothermal entropy change with magnetization, $\Delta s_{\text {mag }}$, was calculated from the magnetization data using a Maxwell relation. Zero-field specific heat, $c_{0}$, was measured in the DSC. Since specific heat, $c$, $\Delta s_{\mathrm{mag}}$, and the adiabatic temperature change, $\Delta T_{\mathrm{ad}}$, are coupled through the entropy curves and the internal magnetic field, once two of these parameters are known then the third can be calculated (Engelbrecht and Bahl, 2010). Entropy curves as a function of temperature and internal magnetic field were implemented in the numerical model. The density of the $\mathrm{Gd}$ was assumed constant as $7901 \mathrm{~kg} / \mathrm{m}^{3}$ and the thermal conductivity was taken as $11 \mathrm{~W} / \mathrm{m}-\mathrm{K}$. 
The demagnetization effects due to the geometry of the sample were not included in the calculations of $\Delta s_{\text {mag }}$ since on the numerical model a demagnetization function was implemented to take into account this effect on the regenerator beds. The function is based on the demagnetization factor, temperature and magnetization characteristics of the magnetocaloric material on the regenerator bed. The internal magnetic field, $H_{\mathrm{int}}$, is calculated from the applied magnetic field, $H_{\text {appl }}$, and demagnetizing field as given in Eq. 1 (Bahl and Nielsen, 2009),

$$
H_{\text {int }}=H_{\text {appl }}-N_{D}^{\text {bed }} M
$$

where $N_{D}^{\text {bed }}$ is the overall average demagnetization factor of the Gd packed-spheres in the bed calculated as (Coey, 2011):

$$
N_{D}^{\text {bed }}=\frac{1}{3}+(1-\varepsilon)\left(N_{\text {bed }}-\frac{1}{3}\right)
$$

where $\varepsilon$ is the porosity (equal to 0.36 ) and $N_{\text {bed }}$ is the geometrical demagnetization factor due to the shape of the bed, in this case calculated to be 0.383 (Aharoni, 1998), then $N_{D}^{\text {bed }}=0.365$.

The fluid used for the experiments is a mixture of $20 \%$ ethylene-glycol in deionised water per volume basis. The thermodynamic properties of this mixture were obtained from Melinder (1997) and implemented in the numerical model as polynomial fits.

The thermal losses in the AMR correspond to losses from the cold end of the AMR to ambient (the room), from both the regenerators and from the external piping and equipments. Of the external components only the connecting pipes were insulated during the experiments in this work.

\section{RESULTS AND DISCUSSION}

Magnetocaloric properties of the commercial Gd spheres employed in the regenerator beds are presented in Fig. 2. A peak of $\Delta s_{\operatorname{mag}}$ of $3.2 \mathrm{~J} / \mathrm{kg}-\mathrm{K}$ at a magnetic field change of $1 \mathrm{~T}$ and $288 \mathrm{~K}$ was measured. Also, the peak of $\Delta T_{\text {ad }}$ of $3.1 \mathrm{~K}$ at $1 \mathrm{~T}$ and $289.6 \mathrm{~K}$ was calculated from entropy and specific heat data. These properties are lower than for those of a pure Gd (Dan'kov et al., 1998) or from the ones calculated with the mean field theory (MFT) (Petersen et al., 2008). The difference is probably due to impurities and possibly corrosion on Gd spheres (Dan'kov et al., 1998). Also, the measured Curie temperature seems to be lower than that published for pure Gd (Pecharsky et al., 2001). Therefore, numerical results obtained with these properties are expected to have lower performance and a lower peak temperature than results obtained with pure Gd properties would have.

The temperature span dependence on the operation frequency for a cooling capacity of $200 \mathrm{~W}$ is shown in Figure 3. This experiment was performed with a constant volumetric flow rate of $500 \mathrm{~L} / \mathrm{h}$, which was measured at the cold end. The chiller temperature was also kept constant in order to maintain $T_{\mathrm{H}}$ at approximately $298 \mathrm{~K}$. A peak on the temperature span of $18.9 \mathrm{~K}$ was attained for an operation frequency of $2.25 \mathrm{~Hz}$. At lower frequencies there is a large influence of the longitudinal thermal conduction (Nielsen et al., 2011) and the regenerator utilization becomes too high. However, it can be seen that at lower frequencies, normally those used in most AMR devices, the temperature span increases with increasing frequency, as observed experimentally in Russek et al. (2010), until a certain optimum frequency from which the irreversible losses become significant and the heat transfer is affected, so the regenerator is not able to maintain a high temperature span. This trend of the temperature span obtained experimentally is in agreement with published numerical results for other conditions (Tusek et al., 2011). 
Fifth IIF-IIR International Conference on Magnetic Refrigeration at Room Temperature, Thermag V Grenoble, France, 17-20 September 2012

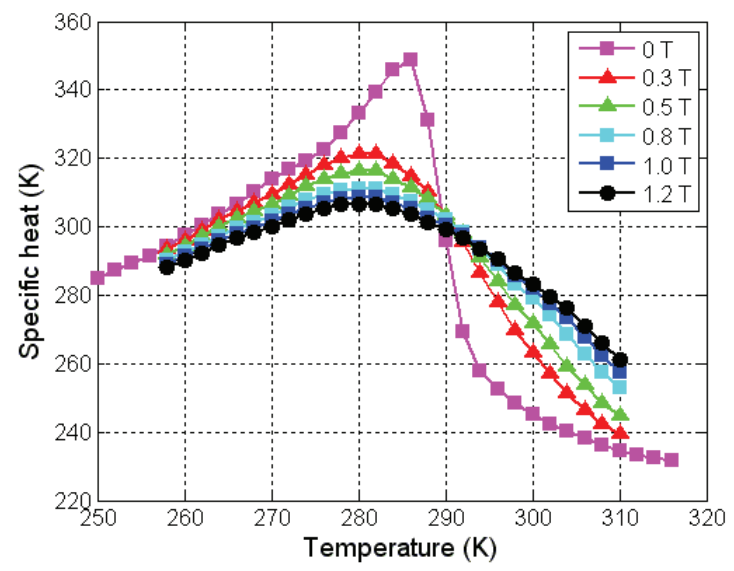

(a)

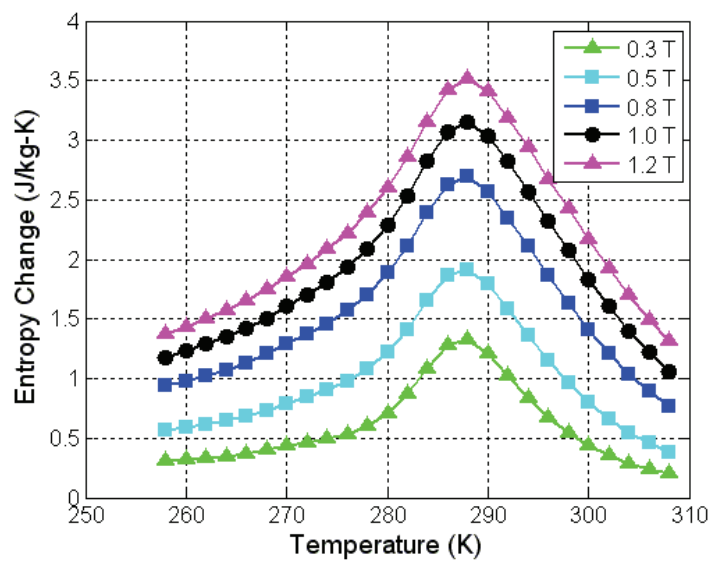

(b)

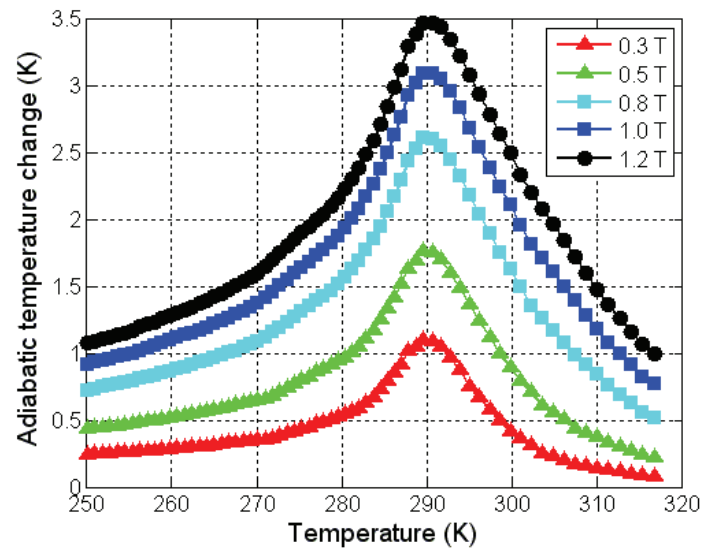

(c)

Figure 2. Properties of commercial Gd spheres used in the regenerator beds (a) Specific heat (zero-field is measured, the other curves are derived from $\Delta s_{\text {mag }}$ from magnetization data and the zero-field specific heat) (b) $\Delta s_{\text {mag }}$ integrated from the specific heat, and (c) $\Delta T_{\text {ad }}$ as a function of temperature and magnetic field (derived from the specific heat and $\Delta s_{\text {mag }}$ data).

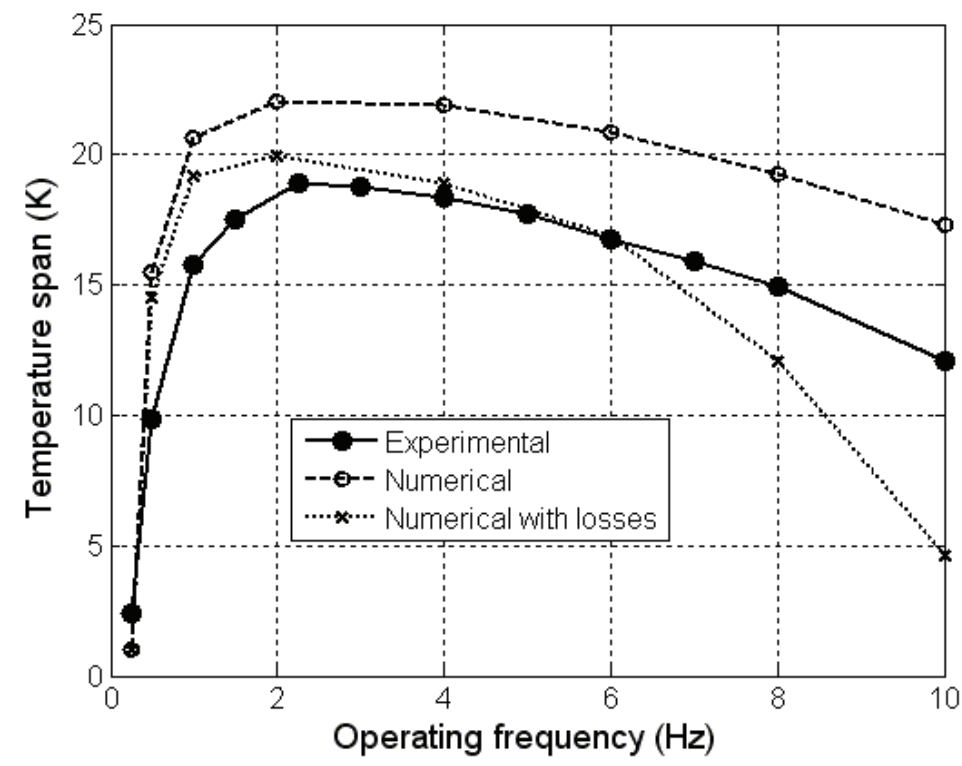

Figure 3. Experimental and numerical results for the temperature span as a function of frequency with a cooling capacity of $200 \mathrm{~W}$ and $T_{H}=298 \mathrm{~K}$. 
A detailed study of the behaviour of the device at high frequencies was carried out by experiments of the temperature span as a function of the cooling capacity at different frequencies. The volumetric flow rate was held constant at $500 \mathrm{~L} / \mathrm{h}$. Due to a lower Curie temperature of the $\mathrm{Gd}$, an improvement of the performance at higher cooling capacities was expected to be obtained at lower $T_{\mathrm{H}}$. Consequently, for this set of experiments the $T_{\mathrm{H}}$ was set at approximately $296 \mathrm{~K}$.

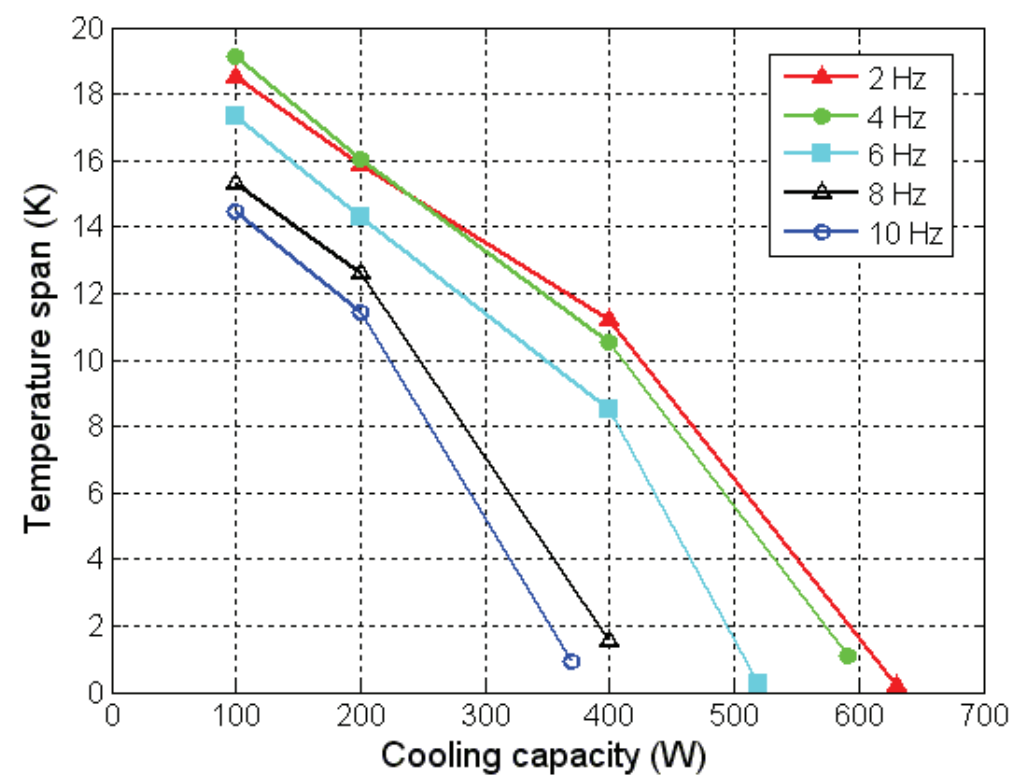

Figure 4. Experimental results of the temperature span as a function of the cooling capacity at different frequencies and $T_{H}=296 \mathrm{~K}$.

These results are in agreement with those in Fig. 3, where the best performance is achieved at a frequency of approximately $2 \mathrm{~Hz}$. This is due mainly to heat generation in the valves at higher frequencies caused by friction between the seals and the flowhead, as well as, other thermal parasitic losses with the ambient. Therefore, a thermal loss analysis was carried out to evaluate their influence on the temperature difference and of the operation conditions of the device at high frequencies. Absolute thermal resistances based on geometrical shape, estimated free convection losses and material properties of the external components were calculated at the cold-end to be $0.23,5.75$ and $13.88 \mathrm{~K} / \mathrm{W}$ for the regenerator, flowhead and connecting tubes, respectively. These thermal losses are considerable at higher temperature spans, when the cold end is working in temperatures lower than the ambient temperature. These losses are post calculated and then deducted from the predicted cooling power of the device. The influences of these losses on the regenerator cycle are therefore not accounted for.

Regarding the losses by friction in the valve, some measurements were carried out to calculate the power that the motor consumes due to this friction, $\dot{W}_{\text {fric }}$. The friction loss is simply the difference in power required to rotate the machine with and without the seals (Eq.3)

$$
\dot{W}_{\text {fric }}=\dot{W}_{\text {sys }}-\dot{W}_{\text {free }}
$$

where $\dot{W}_{\text {sys }}$ correspond to the power used to operate the system with the valves and $\dot{W}_{\text {free }}$ is the power of operation without the valves. Since these powers are a function of frequency and temperature, experiments were performed at room-temperature with no flow and no temperature span, but varying frequencies. It was found that $\dot{W}_{\text {fric }}$ increases almost linearly with frequency and an average of $\dot{W}_{f r} \sim$ $40 \mathrm{~W}$ per $\mathrm{Hz}$ was calculated. This value corresponds to the power consumed due to the valve at both the hot and cold ends of the device. Taking into account that at temperatures below room-temperature 
there is a contraction of the nylon in the flowhead and that only part of the heat generated is dissipated into the cold stream of fluid, the equivalent heat dissipated by the valve to the fluid is assumed to be approximately $10 \mathrm{~W}$ per $\mathrm{Hz}$. Therefore, at $2 \mathrm{~Hz}$ the thermal loss due to the friction at the valve is about $20 \mathrm{~W}$, while at $10 \mathrm{~Hz}$ the loss is approximately $100 \mathrm{~W}$.

As a result, an overall heat loss value was calculated for each experiment as the sum of the thermal parasitic losses on the components and the heat generated by friction on the valve. This heat loss was subtracted from the cooling capacity found by numerical simulation and the results are plotted in Fig. 3 and compared to the experimental results at 2, 4 and $10 \mathrm{~Hz}$.

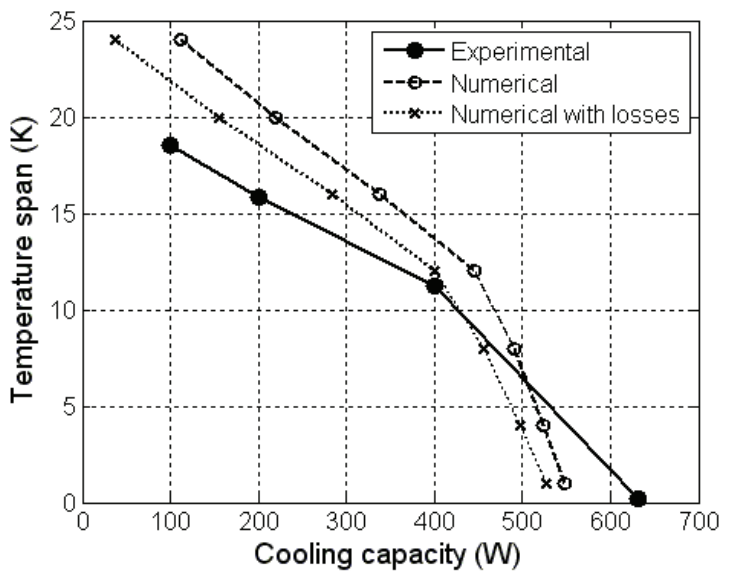

(a)

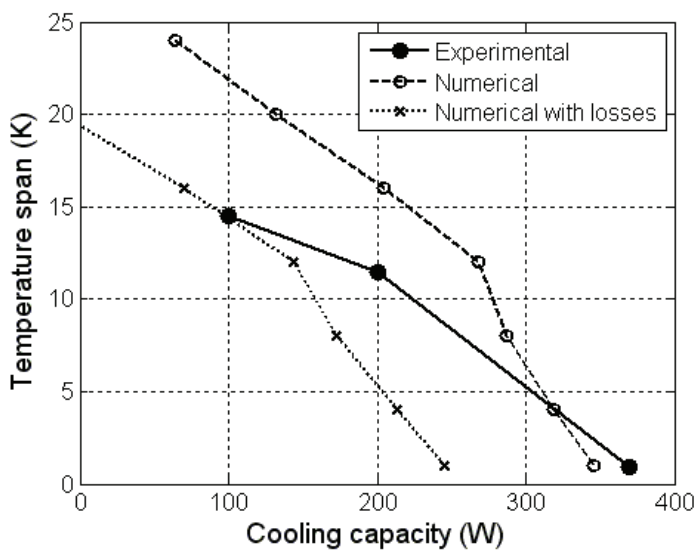

(c)

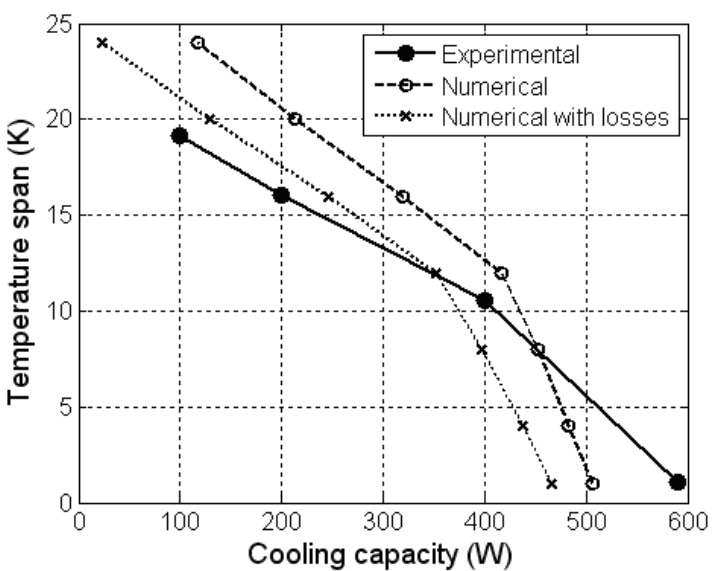

(b)

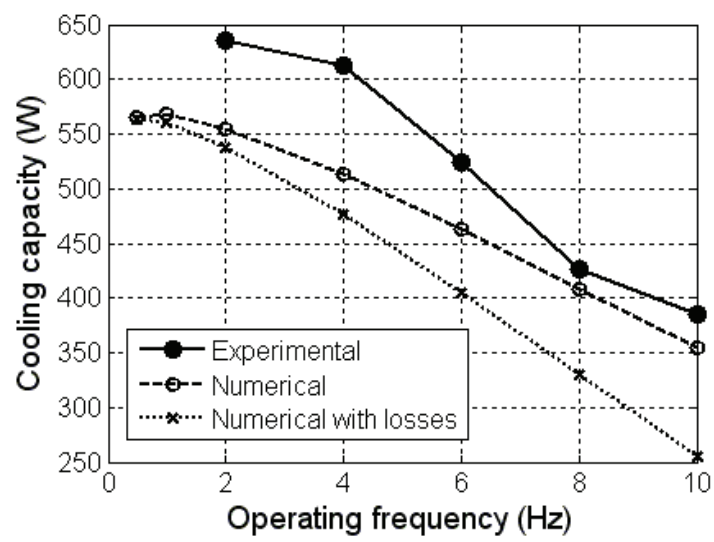

(d)

Figure 5. Comparison of experimental and numerical results at (a) $2 \mathrm{~Hz}$, (b) $4 \mathrm{~Hz}$ and (c) $10 \mathrm{~Hz}$ and (d) Maximum cooling capacity at no-span.

As can be seen in Figs. 3 and 5, there is good agreement between the experimental and numerical results. It is remarkable that both results present a break on the trend at spans of approximately $12 \mathrm{~K}$, which could be explain due to the non-linear magnetocaloric properties of the Gd and that it is the point where these properties become lower. From the numerical results can be inferred that the irreversible thermal losses increase with the frequency. At low cooling capacities, or high temperature spans, the model over predicts the measured results. This may be related to the fact that the numerical model does not include some other thermal losses, such as those at the boundaries of the regenerator bed (in this model they are considered adiabatic), where a heat leak is present with the housing and ambient which becomes higher when the cold end is below room-temperature. Nielsen et al. (2009) affirmed that this effect may have a considerable impact on the AMR performance. Other types of thermal losses not taken into account in this work are the magnetic losses in Gd beds due to the parasitic currents produced by the magnetization and demagnetization of the magnetic material at relative higher frequencies. At the cold-end there are other heat sinks in the device such as the filter, valve and mass flowmeter which were not included in the calculations. There are other uncertainties in 
the numerical model such as the particle size distribution which was employed. It was found that a 0.6 $\mathrm{mm}$ sphere diameter results in good agreement with the experiment, but a detailed study of the particle diameter is not presented here.

From this thermal analysis some design improvements for further AMR devices operating at higher frequencies are proposed. First, some effort should be taken into account for the design of the valves or system that allows oscillatory flow in the regenerator beds and valve friction must be avoided as much as possible. Good thermal insulation should be used in the cold end and along the regenerator beds to avoid heat leaks while working below room-temperature.

It was proven through modelling in this work, as Tusek et al. (2011) proposed, that smaller sphere diameters lead to higher temperature spans and cooling capacities at high frequencies, due to an increase in heat transfer area and heat transfer coefficient. However, decreasing particle size represents a pronounced increase in viscous losses and pressure drop along the bed increasing pumping power and thus decreasing the performance of the device.

\section{CONCLUSION}

Experimental and numerical results for a high frequency rotating active magnetic refrigerator were obtained. Temperature span was measured at frequencies up to $10 \mathrm{~Hz}$. An experimental peak on the temperature span of $18.9 \mathrm{~K}$ with $200 \mathrm{~W}$ cooling capacity was attained at $2.25 \mathrm{~Hz}$. The observed trend of the experimental temperature span agrees well with that published in the literature for both experimental and numerical data. A thermal analysis was performed to evaluate the thermal losses which have higher impacts on the performance of the device, such as the heat generated due to friction at the valve and the thermal leaks to the ambient. The former is directly proportional to the frequency while the latter depends on the temperature difference from the ambient. These losses were taken into account in the 1D AMR model, and the results agree well the experimental data for temperature span as a function of frequency and cooling capacity. A more efficient valve design is proposed to improve the performance of the device at high frequencies, better insulation at the cold end and smaller sphere diameters are proposed as improvements for future AMR devices working at high frequencies.

\section{ACKNOWLEDGEMENTS}

The authors would like to acknowledge the support of the Programme Commission on Energy and Environment (EnMi) (Contract No. 2104-06-0032) which is part of the Danish Council for Strategic Research. The authors thank Jørgen Geyti for technical assistance. J.A. Lozano, J.R. Barbosa and A.T. Prata thank the financial support from CNPq (Brazil) through Grant No. 18573581/2008-8 (National Institute of Science and Technology in Cooling and Thermophysics). K.K. Nielsen wishes to thank The Danish Council for Independent Research | Technology and Production Sciences (Contract no. 10-092791) for financial support.

\section{REFERENCES}

Aharoni, A., 1998, Demagnetizing factors for rectangular ferromagnetic prisms, J. Appl. Physics., 86, 6, 3432-3434.

Bahl, C.R.H., Engelbrecht, K., Bjørk, R., Eriksen, D., Smith, A., Nielsen, K.K., Pryds, N., 2011, Design concepts for a continuously rotating active magnetic regenerator, Int. J. Refrig., 34, 8, 17921796. 
Bahl, C.R.H., Engelbrecht, K., Eriksen, D., Lozano, J.A., Bjørk, R., Geyti, J., Nielsen, K.K., Smith, A., Pryds, N., 2012, Development and experimental results from a $1 \mathrm{~kW}$ near continuous prototype AMR, Proc. 5th Int. Conference on Magnetic Refrigeration at Room Temperature.

Bjørk, R., Bahl, C.R.H., Smith, A., Christensen, D. V., Pryds, N., 2010, An optimized magnet for magnetic refrigeration, Journal of Magnetism and Magnetic Materials, 322, 3324-3328.

Coey, J.M., 2010, Magnetism and magnetic materials, Cambridge University Press.

Dan'kov, S.Y., Tishin, A.M., Pecharsky, V.K., Gschneidner Jr., K.A., 1998, Magnetic phase transitions and the magnetothermal properties of gadolinium, Physical Review B, vol. 57, n. 6, 34783490.

Engelbrecht, K., Nellis, G., Klein, S., and Zimm, C. 2007, Recent Developments in Room Temperature Active Magnetic Regenerative Refrigeration, HVAC\&R Research, 13(4): 525 - 542.

Engelbrecht, K. and Bahl, C.R.H, 2010, Evaluating the effect of magnetocaloric properties on magnetic refrigeration performance, J. Appl. Physics, 108: 123918.

Engelbrecht, K., Eriksen, D., Bahl, C.R.H., Bjørk, R., Geyti, J., Lozano, J.A., Nielsen, K.K., Saxild, F., Smith, A., Pryds, N., 2012, Experimental results for a novel rotary active magnetic regenerator, Int. J. Refrig., vol. 35, n. 6, 1498-1505.

Jeppesen, S., Linderoth, S., Pryds, N., Theil Kuhn, L., Buch Jensen, J., 2008, Indirect measurement of the magnetocaloric effect using a novel differential scanning calorimeter with magnetic field, Review of Scientific Instruments, 79, 083901.

Kaviany, M., 1995, Principles of Heat Transfer in Porous Media, Springer, New York.

Melinder, A., 1997, Thermophysical properties of liquid secondary refrigerants, International Institute of Refrigeration, Paris.

Nielsen, K.K., Bahl, C.R.H., Bjørk, R., Pryds, N., Smith, A., Hattel, J., 2009. Detailed numerical modeling of a linear parallel-plate active magnetic regenerator. Int. J. Refrig., 32, 1478-1486.

Nielsen, K.K., Tusek, J., Engelbrecht, K., Schopfer, S., Kitanovski, A., Bahl, C.R.H., Smith, A., Pryds, N., Poredos, A.,2011. Review on numerical modeling of active magnetic regenerators for room temperature applications. Int. J. Refrig., 34 (3), 603-616.

Pecharsky, V.K., Gschneidner, K.A., Pecharsky, A.O. and Tishin, A.M., 2001, Thermodynamics of the magnetocaloric effect. Physical Review B, 64(14):144406/1-13.

Petersen, T.F., Pryds, N., Smith, A., Hattel, J., Schmidt, H., and Knudsen, H.J.H., 2008, Twodimensional mathematical model of a reciprocating room-temperature Active Magnetic Regenerator, Int. J. Refrig., 31, 432-443.

Russek, S., Auringer, J., Boeder, A., Chell, J., Jacobs, S., Zimm, C., 2010. The performance of a rotary magnet magnetic refrigerator with layered beds. Proc. 4th Int. Conference on Magnetic Refrigeration at Room Temperature, Baotou, Inner Mongolia, China, 339-349.

Tusek, J., Kitanovski, A., Prebil, I., Poredos, A., 2011, Dynamic operation of an active magnetic regenerator (AMR): Numerical optimization of a packed-bed AMR, Int. J. Refrig., 34, 1507-1517.

Yu, B., Liu, M., Egolf, P.W., Kitanovski, A., 2010. A review of magnetic refrigerator and heat pump prototypes built before the year 2010. Int. J. Refrig., 33, 1029-1060. 